\title{
Estado serológico frente a Toxoplasma gondii en receptores de trasplante cardiaco: ¿un factor pronóstico independiente?
}

\author{
Eduardo Barge-Caballero a,b ${ }^{\text {ab }}$ Cayetana Barbeito-Caamaño ${ }^{\mathrm{a}, \mathrm{b}}$, Gonzalo Barge- \\ Caballero ${ }^{\text {a,b }}$, David Couto-Mallón ${ }^{\text {a,b }}$, María J. Paniagua-Martín ${ }^{\text {a,b }}$, Raquel \\ Marzoa-Rivas a,b $^{\text {a,b }}$, Miguel Solla-Buceta ${ }^{\text {b,c }}$, Francisco Estévez-Cid ${ }^{\text {b,d }}$, José M. \\ Herrera-Noreña ${ }^{\text {b,d }}$, José J. Cuenca-Castillo ${ }^{\text {b,d }}$, José M. Vázquez-Rodríguez ${ }^{\text {a,b }}$, \\ María G. Crespo-Leiro a,b
}

\footnotetext{
${ }^{a}$ Servicio de Cardiología, Complejo Hospitalario Universitario A Coruña, A Coruña, España

${ }^{b}$ Instituto de Investigación Biomédica de A Coruña (INIBIC), A Coruña, España

${ }^{c}$ Servicio de Medicina Intensiva, Complejo Hospitalario Universitario A Coruña, A Coruña, España

${ }^{d}$ Servicio de Cirugía Cardiaca, Complejo Hospitalario Universitario A Coruña, A Coruña, España
}

\begin{abstract}
Resumen
Introducción y objetivos.

Analizar la influencia pronóstica del estado serológico frente a Toxoplasma gondii en receptores de trasplante cardiaco (TC).

Métodos

Se realizó un estudio retrospectivo unicéntrico con 657 receptores de TC entre 1991 y 2015. Mediante dos modelos multivariantes de Cox se comparó la supervivencia y la incidencia de episodios clínicos adversos de los receptores seropositivos $(\mathrm{n}=481)$ y los receptores seronegativos $(\mathrm{n}=176)$ frente a $T$. gondii. El modelo 1 incluyó edad y sexo, y el modelo 2 incluyó otros factores de confusión potenciales.

Resultados

Con una mediana de seguimiento de 2.903 días (rango intercuartílico: 898-4.757), fallecieron 250 pacientes seropositivos $(52 \%)$ y 72 receptores seronegativos $(41 \%)$ frente a $T$. gondii. Los pacientes seropositivos presentaron mayor mortalidad no ajustada tras el TC (hazard ratio $[\mathrm{HR}]=1,31$; intervalo de confianza del 95\% [IC95\%], 1,00-1,70). Tras el ajuste multivariante, este efecto perdió su significación estadística (modelo 1: HR = 1,09; IC95\%, 0,83-1,43; modelo 2: HR = 1,12; IC95\%, 0,85-1,47). La seropositividad frente a $T$. gondii del receptor se asoció de modo independiente con mayor riesgo de rechazo agudo (modelo 1 : $\mathrm{HR}=1,36$; IC95\%, 1,06-1,74; modelo 2: HR =1,29; IC95\%, 1,01-1,66). Los modelos multivariantes no pusieron de manifiesto una influencia significativa del estado serológico frente a $T$. gondii del receptor sobre la incidencia de infección, neoplasias, enfermedad vascular del injerto o el desenlace combinado muerte cardiaca o retrasplante. Tampoco se observó una influencia pronóstica significativa de la concordancia donante-receptor respecto al estado serológico frente a $T$. gondii.

Conclusiones

El presente estudio no ha puesto de manifiesto un efecto pronóstico independiente del estado serológico frente a $T$. gondii en los receptores de TC.
\end{abstract}

Palabras clave

Trasplante cardiaco. Toxoplasma gondii. Pronóstico. Supervivencia. 


\section{INTRODUCCIÓN}

El trasplante cardiaco (TC) mejora la supervivencia y la calidad de vida en pacientes con insuficiencia cardiaca refractaria que no presentan contraindicaciones absolutas ${ }^{1}$. Para optimizar el proceso de selección de candidatos, es importante reconocer los factores que incrementan el riesgo de mortalidad tras el TC.

La cuestión de si el estado serológico preoperatorio frente a Toxoplasma gondii es un factor pronóstico independiente en los receptores de TC o no continúa siendo un motivo de debate ${ }^{2}$. Hace unos años, un primer estudio unicéntrico observacional ${ }^{3}$ mostró una reducción significativa de la supervivencia tras el TC en receptores seropositivos frente a $T$. gondii en comparación con los receptores seronegativos; este efecto parecía atribuible a mayor incidencia de enfermedad vascular del injerto y riesgo de muerte por esta complicación. Sin embargo, dos estudios unicéntricos posteriores $^{4,5}$ no pudieron confirmar los hallazgos previos ${ }^{3}$. Ninguno de los tres estudios publicados hasta la fecha ha puesto de manifiesto una influencia significativa del estado serológico frente a $T$. gondii del donante o la concordancia donante-receptor respecto a esta condición sobre el pronóstico tras el $\mathrm{TC}^{3,4,5}$.

En vista de la controversia existente, el propósito de este trabajo fue estudiar el potencial impacto del estado serológico frente a $T$. gondii de los receptores de TC sobre el pronóstico a largo plazo tras esta intervención.

\section{MÉTODOS}

\section{Descripción del estudio}

Se realizó un estudio retrospectivo observacional basado en la cohorte histórica de receptores de TC del Complejo Hospitalario Universitario A Coruña, desde el inicio del programa en abril de 1991 hasta febrero de 2015. La información para el estudio se obtuvo a partir de una base de datos local. Para el presente análisis, se seleccionaron los pacientes de los cuales se conocía el estado serológico frente a $T$. gondii previo al TC.

En el hospital, la evaluación del estado serológico frente a $T$. gondii se realiza en la actualidad mediante inmunoanálisis (Elecsys Toxo IgG, Roche Diagnostics) y el resultado se considera positivo en caso de detección de inmunoglobulinas $\mathrm{G}(\mathrm{IgG})$ específicas frente a $T$. gondii con una concentración > $3 \mathrm{UI} / \mathrm{ml}$. En el pasado, se utilizaron otros kits comerciales de inmunoanálisis para detección de IgG específicas con menor sensibilidad. La técnica de avidez por las IgG no se encuentra disponible por el momento en el centro.

Se compararon las características basales y el pronóstico tras el TC de los receptores seropositivos con los de los pacientes seronegativos frente a T. gondii. El Comité Autonómico de Ética en la Investigación Clínica de Galicia aprobó el protocolo del estudio.

\section{Protocolo clínico}

El tratamiento y el seguimiento de los pacientes se realizaron de acuerdo con el protocolo del centro. Durante el periodo posoperatorio se administró tratamiento de inducción con muromonabCD3 o basiliximab. El régimen inmunosupresor de mantenimiento consistió en diferentes combinaciones de esteroides, anticalcineurínicos (ciclosporina o tacrolimus), agentes antiproliferativos (azatioprina o micofenolato mofetilo) y/o inhibidores de m-TOR (sirolimus o everolimus). 
Durante el primer año tras el TC se realizaron biopsias endomiocárdicas habituales; a partir de ese momento, únicamente en caso de sospecha clínica de rechazo agudo. En pacientes estables se realizaron visitas clínicas, que incluían electrocardiograma y ecocardiograma cada 3-6 meses una vez que hubo transcurrido el primer año tras el TC. Se realizaron coronariografías para detección sistemática de enfermedad vascular del injerto en los pacientes con sospecha clínica y, desde el año 2003, también en pacientes asintomáticos, al mes, al año, a los 5 años y a los 10 años tras el TC.

En el centro, todos los receptores seronegativos frente a $T$. gondii que reciben un injerto cardiaco de un donante seropositivo o con estado serológico desconocido son tratados con pirimetamina (25 mg diarios) y ácido folínico (15 mg diarios) vía oral durante los primeros 6 meses tras el TC. Además, todos los receptores de TC reciben quimioprofilaxis frente a Pneumocystis jirovecii con sulfametoxazol-trimetoprim oral (800/160 mg diarios) al menos durante los primeros 12 meses tras el TC.

\section{Desenlaces}

El seguimiento de los pacientes del estudio se extendió desde la fecha del TC hasta la fecha de su muerte o de un nuevo TC; en caso contrario, se cerró a día 30 de abril de 2015. El desenlace principal del estudio fue la mortalidad total tras el TC. Otros desenlaces analizados fueron el combinado muerte cardiaca o retrasplante cardiaco, rechazo agudo, enfermedad vascular del injerto, infección y neoplasias.

Las causas de muerte se recogieron a partir de informes de autopsia o certificados médicos de defunción. Se definió muerte cardiaca como cualquier muerte causada por insuficiencia cardiaca, isquemia miocárdica o arritmia, incluyendo las causadas por disfunción primaria del injerto, rechazo agudo o enfermedad vascular del injerto, así como cualquier muerte súbita inexplicada. El desenlace neoplasia incluyó cualquier neoplasia maligna sólida, cutánea o linfoide. El desenlace infección se definió como cualquier infección probada microbiológicamente o sospechada que hubiera requerido ingreso hospitalario y/o tratamiento antibiótico intravenoso. El desenlace rechazo agudo se definió como cualquier episodio de rechazo agudo celular de grado $\geq 2 \mathrm{R}^{6}$, sintomático o no; o un episodio de rechazo agudo humoral de grado pAMR (antibody-mediated rejection $) \geq 1^{7}$, acompañado de síntomas clínicos de insuficiencia cardiaca y/o disfunción sistólica del injerto, o cualquier episodio de rechazo agudo sospechado no probado por biopsia que hubiese necesitado tratamiento con bolos de esteroides intravenosos, plasmaféresis, inmunoglobulina intravenosa o timoglobulina. Se definió enfermedad vascular del injerto por la existencia de alguna estenosis $\geq 50 \%$ del diámetro luminal de alguno de los 3 vasos coronarios epicárdicos principales o de sus ramas, detectada mediante coronariografía o evidenciada post mortem (únicamente en caso de ser considerada la causa principal del fallecimiento de acuerdo con los hallazgos necrópsicos).

\section{Análisis estadístico}

En este trabajo, las variables cualitativas se presentan como media \pm desviación estándar o mediana (rango intercuartílico), según su adecuación a la normalidad, y las variables categóricas como proporciones. Las características basales de los pacientes seropositivos y seronegativos frente a $T$. gondii se compararon con los test de $\chi^{2}, \mathrm{t}$ de Student o $\mathrm{U}$ de Man-Whitney según correspondiese.

El efecto del estado serológico frente a $T$. gondii del receptor sobre cada uno de los desenlaces analizados se ajustó mediante dos modelos de regresión de Cox multivariante. En el modelo 1 se incluyeron la edad y el sexo del receptor junto con el estado serológico frente a $T$. gondii del receptor. En el modelo 2 se incluyeron las variables del modelo 1 junto con las variables que 
demostraron una asociación estadística independiente con el suceso analizado ( $\mathrm{p}<0,05)$, así como otras variables con distribución asimétrica entre los dos grupos de estudio que se consideraron potenciales factores de confusión según la experiencia clínica y la bibliografía previa. El modelo 2 se utilizó, además, para explorar una potencial influencia del estado serológico frente a T. gondii del donante sobre la mortalidad tras el TC. Se estableció un nivel de significación de $\mathrm{p}<0,05$. El análisis estadístico se realizó con SPSS 20.

\section{RESULTADOS}

\section{Población del estudio}

En el centro, 703 pacientes recibieron un TC entre abril de 1991 y febrero de 2015. El estado serológico frente a $T$. gondii del receptor antes del TC era conocido en 657 (93\%) pacientes y fue positivo en 481 (73\%). Cuarenta y seis (7\%) receptores con estado serológico frente a T. gondii desconocido fueron excluidos del análisis.

La tabla 1 muestra una comparación de las características clínicas basales de los receptores en función de su estado serológico frente a $T$. gondii. Los pacientes seropositivos eran mayores y presentaban mayor índice de masa corporal y mayor prevalencia de diabetes y seropositividad frente a citomegalovirus, mientras que el empleo de medidas de soporte vital preoperatorio fue más frecuente en pacientes seronegativos. Además, una mayor proporción de pacientes seronegativos recibió tratamiento inicial con tacrolimus. 
Tabla 1. Características clínicas basales de los pacientes del estudio

\begin{tabular}{|c|c|c|c|}
\hline & $\begin{array}{l}\text { Receptores } \\
\text { seronegativos frente a } \\
T . \text { gondii, } \mathrm{n}=176\end{array}$ & $\begin{array}{l}\text { Receptores } \\
\text { seropositivos frente } \\
\text { a } T . \text { gondii, } \mathrm{n}=481\end{array}$ & $\mathrm{p}$ \\
\hline Edad (años) & $48,1 \pm 16,4$ & $56,1 \pm 18,9$ & $<0,001$ \\
\hline Índice de masa corporal $\left(\mathrm{kg} / \mathrm{m}^{2}\right)$ & $25,2 \pm 4,2$ & $26,0 \pm 4,1$ & 0,043 \\
\hline Mujer (\%) & 21 & 16 & 0,204 \\
\hline Cardiopatía isquémica (\%) & 38 & 41 & 0,451 \\
\hline Historia de tabaquismo (\%) & 48 & 52 & 0,335 \\
\hline Diabetes mellitus (\%) & 11 & 18 & 0,018 \\
\hline Hipertensión (\%) & 36 & 46 & 0,025 \\
\hline Cirugía cardiaca previa (\%) & 20 & 25 & 0,145 \\
\hline Receptor seropositivo frente a citomegalovirus (\%) & 69 & 89 & $<0,001$ \\
\hline Desfibrilador (\%) & 17 & 15 & 0,515 \\
\hline Agentes inotrópicos $(\%)$ & 28 & 20 & 0,042 \\
\hline Balón intraaórtico (\%) & 21 & 14 & 0,039 \\
\hline Asistencia ventricular (\%) & 3 & 1 & 0,067 \\
\hline ECMO (\%) & 1 & 1 & 0,935 \\
\hline Diálisis (\%) & 2 & 2 & 0,971 \\
\hline Ventilación mecánica (\%) & 17 & 11 & 0,041 \\
\hline Creatinina (mg/dl) & $1,35 \pm 0,70$ & $1,32 \pm 0,70$ & 0,443 \\
\hline Retrasplante (\%) & 1 & 2 & 0,145 \\
\hline Trasplante multiorgánico (\%) & 3 & 4 & 0,748 \\
\hline Tiempo de isquemia (min) & $195,1 \pm 75,6$ & $188,3 \pm 77,7$ & 0,319 \\
\hline Donante mujer (\%) & 26 & 26 & 0,956 \\
\hline Edad del donante (años) & $36,2 \pm 14,0$ & $37,4 \pm 14,1$ & 0,345 \\
\hline Donante seropositivo frente a $T$. gondii & 31 & 33 & 0,912 \\
\hline Uso de ciclosporina (\%) & 65 & 76 & 0,003 \\
\hline Uso de tacrolimus (\%) & 26 & 17 & 0,014 \\
\hline Uso de micofenolato mofetilo (\%) & 54 & 58 & 0,372 \\
\hline Uso de azatioprina (\%) & 35 & 36 & 0,861 \\
\hline Uso de everolimus o sirolimus (\%) & 3 & 2 & 0,170 \\
\hline
\end{tabular}

ECMO: oxigenador extracorpóreo de membrana.

Los valores expresan porcentaje o media \pm desviación estándar.

\section{Supervivencia tras el trasplante}

El seguimiento de los pacientes se realizó durante una media de 2.903 días (rango intercuartílico: 898-4.757) tras el TC. Durante este periodo, 322 (49\%) pacientes fallecieron y 9 (1\%) recibieron un segundo TC. La muerte fue de origen cardiaco en $137(41 \%)$ pacientes y de origen no cardiaco en 185 (59\%). La distribución de las causas de muerte en función del estado serológico frente a $T$. gondii se presenta en la tabla 2. 
Tabla 2. Causas de muerte en receptores seropositivos y receptores seronegativos frente a Toxoplasma gondii

\begin{tabular}{lll}
\hline & $\begin{array}{l}\text { Receptores seronegativos } \\
\text { frente a } T . \text { gondii, } \mathrm{n}=72\end{array}$ & $\begin{array}{l}\text { Receptores seropositivos } \\
\text { frente a } T . \text { gondii, } \mathrm{n}=250\end{array}$ \\
\hline Muerte de causa cardiaca (\%) & & $104(42)$ \\
Fracaso primario del injerto (precoz) & $33(46)$ & 23 \\
Rechazo agudo & 13 & 12 \\
Enfermedad vascular del injerto & 5 & 29 \\
Muerte súbita & 8 & 33 \\
Fracaso inespecífico del injerto (tardío) & 7 & 7 \\
Muerte de causa no cardiaca (\%) & 0 & $146(58)$ \\
Infección & $39(54)$ & 47 \\
Neoplasia & 6 & 53 \\
Enfermedad vascular & 8 & 9 \\
Fallo multiorgánico no especificado & 8 & 8 \\
Otras & 5 & 29 \\
& 12 &
\end{tabular}

Los pacientes seropositivos frente a $T$. gondii presentaron una mortalidad total no ajustada significativamente mayor que la de los pacientes seronegativos (hazard ratio [HR] univariante $=1,31$; intervalo de confianza del 95\% [IC95\%], 1,00-1,70). Sin embargo, este efecto perdió su significación estadística tras el ajuste multivariante. El HR de mortalidad total ajustado por edad y sexo del receptor (modelo multivariante 1) fue 1,09 (IC95\%, 0,83-1,43; tabla 3). No se observaron cambios relevantes en esta asociación cuando el ajuste incluyó otros factores de confusión potenciales (modelo multivariante 2: $\mathrm{HR}=1,12$; IC95\%, 0,85-1,47; tabla 3). Los modelos multivariantes de regresión de Cox de mortalidad total se muestran en la tabla 4. 
Tabla 3. Resumen de sucesos del estudio

\begin{tabular}{|c|c|c|c|c|c|}
\hline Sucesos, n (\%) & $\begin{array}{l}\text { Receptores } \\
\text { seropositivos frente a } T \text {. } \\
\text { gondii, } \mathrm{n}=481\end{array}$ & $\begin{array}{l}\text { Receptores } \\
\text { seronegativos frente a } T \text {. } \\
\text { gondii, } \mathrm{n}=176\end{array}$ & $\begin{array}{l}\mathrm{HR} \\
\text { univariante }\end{array}$ & $\begin{array}{l}\text { HR } \\
\text { multivariante } \\
\text { modelo } 1\end{array}$ & $\begin{array}{l}\text { HR multivariante } \\
\text { modelo } 2^{*}\end{array}$ \\
\hline $\begin{array}{l}\text { Muerte por } \\
\text { cualquier causa }\end{array}$ & $250(52,0)$ & $72(40,9)$ & $\begin{array}{l}1,31(1,00- \\
1,70)\end{array}$ & $1,09(0,83-1,43)$ & $1,12(0,85-1,47)$ \\
\hline $\begin{array}{l}\text { Muerte cardiaca } \\
\text { o retrasplante }\end{array}$ & $112(23,3)$ & $34(19,3)$ & $\begin{array}{l}1,21(0,82- \\
1,78)\end{array}$ & $1,16(0,77-1,73)$ & $1,13(0,76-1,69)$ \\
\hline Neoplasia & $129(26,8)$ & $29(16,5)$ & $\begin{array}{l}1,84(1,23- \\
2,76)\end{array}$ & $1,32(0,88-1,99)$ & $1,31(0,87-1,98)$ \\
\hline Infección & $189(39,3)$ & $67(38,1)$ & $\begin{array}{l}1,04(0,78- \\
1,37)\end{array}$ & $0,94(0,71-1,26)$ & $0,92(0,68-1,24)$ \\
\hline Rechazo agudo & $297(61,7)$ & $88(50,0)$ & $\begin{array}{l}1,39(1,09- \\
1,76)\end{array}$ & $1,36(1,06-1,74)$ & $1,29(1,01-1,66)$ \\
\hline $\begin{array}{l}\text { Enfermedad } \\
\text { vascular del } \\
\text { injerto }\end{array}$ & $89(18,5)$ & $34(19,3)$ & $\begin{array}{l}1,02(0,69- \\
1,52)\end{array}$ & $0,91(0,60-1,38)$ & $0,87(0,57-1,32)$ \\
\hline
\end{tabular}

HR: hazard ratio.

La estimación de HR ha tomado en cuenta a los pacientes seronegativos frente a $T$. gondii como categoría de referencia.

* Covariantes incluidas en los modelos:Muerte por cualquier causa: estado serológico frente a T. gondii del receptor, diabetes, hipertensión arterial, sexo del receptor, edad del receptor, cirugía cardiaca previa, creatinina, estado serológico frente a citomegalovirus del receptor, índice de masa corporal, balón de contrapulsación, agentes inotrópicos, ventilación mecánica, micofenolato mofetilo y tacrolimus.Muerte por causa cardiaca o retrasplante: estado serológico frente a T. gondii del receptor, diabetes, hipertensión arterial, sexo del receptor, edad del receptor, estado serológico frente a citomegalovirus del receptor, índice de masa corporal, balón de contrapulsación, desfibrilador, agentes inotrópicos, ventilación mecánica, micofenolato mofetilo y tacrolimus.Neoplasia: estado serológico frente a $T$. gondii del receptor, sexo del receptor, edad del receptor, tabaquismo, estado serológico frente a citomegalovirus del receptor, índice de masa corporal y tacrolimus.Infección: estado serológico frente a $T$. gondii del receptor, diabetes, hipertensión arterial, sexo del receptor, edad del receptor, edad del donante, estado serológico frente a citomegalovirus del receptor, índice de masa corporal, balón de contrapulsación, agentes inotrópicos, ventilación mecánica, micofenolato mofetilo y tacrolimus.Rechazo agudo: estado serológico frente a $T$. gondii del receptor, sexo del receptor, edad del receptor, tabaquismo, trasplante multiorgánico, estado serológico frente a citomegalovirus del receptor, índice de masa corporal, micofenolato mofetilo y tacrolimus.Enfermedad vascular del injerto: estado serológico frente a $T$. gondii del receptor, diabetes, hipertensión arterial, sexo del receptor, edad del receptor, edad del donante, estado serológico frente a citomegalovirus del receptor, índice de masa corporal y tacrolimus. 
Tabla 4. Análisis de supervivencia tras el trasplante cardiaco: modelos de regresión de Cox multivariante

\begin{tabular}{|c|c|c|c|}
\hline Variante & HR & IC95\% & $\mathrm{p}$ \\
\hline \multicolumn{4}{|l|}{ Modelo multivariante 1} \\
\hline Receptor seropositivo frente a $T$. gondii & 1,09 & $0,83-1,43$ & 0,516 \\
\hline Mujer & 0,67 & $0,48-0,92$ & 0,014 \\
\hline Edad del receptor (por 1 año) & 1,023 & $1,012-1,024$ & $<0,001$ \\
\hline \multicolumn{4}{|l|}{ Modelo multivariante 2} \\
\hline Receptor seropositivo frente a $T$. gondii & 1,12 & $0,85-1,47$ & 0,419 \\
\hline Edad del receptor (por 1 año) & 1,023 & $1,010-1,036$ & $<0,001$ \\
\hline Micofenolato mofetilo & 0,52 & $0,40-0,67$ & $<0,001$ \\
\hline Creatinina (por $1 \mathrm{mg} / \mathrm{dl}$ ) & 1,165 & $1,061-1,278$ & $<0,001$ \\
\hline Diabetes mellitus & 1,92 & $1,43-2,58$ & $<0,001$ \\
\hline Cirugía cardiaca previa & 1,38 & $1,08-1,78$ & 0,012 \\
\hline Hipertensión & 0,46 & $0,36-0,58$ & $<0,001$ \\
\hline Mujer & 0,69 & $0,49-0,98$ & 0,035 \\
\hline Balón intraaórtico & 0,52 & $0,29-0,96$ & 0,036 \\
\hline Agentes inotrópicos & 1,62 & $1,08-2,44$ & 0,020 \\
\hline Ventilación mecánica & 1,03 & $0,58-1,85$ & 0,912 \\
\hline Receptor seropositivo frente a citomegalovirus & 0,88 & $0,63-1,22$ & 0,446 \\
\hline Tacrolimus & 0,98 & $0,66-1,46$ & 0,933 \\
\hline Índice de masa corporal (por $1 \mathrm{~kg} / \mathrm{m}^{2}$ ) & 1,011 & $0,979-1,043$ & 0,929 \\
\hline
\end{tabular}

IC95\%: intervalo de confianza del 95\%; HR: hazard ratio.

\section{Otros desenlaces}

No se observaron diferencias estadísticamente significativas entre los receptores seropositivos y los receptores seronegativos frente a $T$. gondii respecto a la incidencia acumulada del desenlace combinado muerte cardiaca o retrasplante, ni en el análisis univariante ( $\mathrm{p}$ log rank $=0,331$; $\mathrm{HR}=1,21$; IC95\%, 0,82-1,78) ni en los modelos multivariantes (modelo 1: HR = 1,16; IC95\%, 0,77-1,73; modelo 2: HR = 1,13; IC95\%, 0,76-1,69; tabla 3).

El análisis univariante reveló un incremento estadísticamente significativo de la incidencia acumulada de rechazo agudo en los pacientes seropositivos frente a T. gondii (p log rank $=0,007$; $\mathrm{HR}=1,39$; IC95\%, 1,09-1,76), que se mantuvo en los análisis multivariantes (modelo 1: $\mathrm{HR}=1,36$; IC95\%, 1,06-1,74; modelo 2: HR = 1,29; IC95\%, 1,01-1,66).

El análisis univariante también mostró un incremento del riesgo de neoplasias en los pacientes seropositivos frente a $T$. gondii (p log rank =0,003; HR = 1,84; IC95\%, 1,23-2,76). Sin embargo, esta asociación perdió su significación estadística tras el ajuste multivariante (modelo 1: $\mathrm{HR}=1,32$; IC95\%, 0,88-1,99; modelo 2: HR = 1,31; IC95\%, 0,87-1,98).

No se observaron diferencias estadísticamente significativas en función del estado serológico frente a $T$. gondii respecto a la incidencia acumulada de enfermedad vascular del injerto (p log rank $=0,920 ;$ HR univariante $=1,02 ;$ IC95\%, 0,69-1,52) o infecciones (p log rank=0,808; HR univariante $=1,04$; IC95\%, 0,78-1,37), ni en el análisis univariante ni con los diferentes modelos multivariantes. 


\section{Concordancia donante-receptor respecto al estado serológico frente a Toxoplasma gondii}

El estado serológico frente a $T$. gondii del donante cardiaco era conocido en $441(67 \%)$ de los trasplantes y fue positivo en $323(73 \%)$ de ellos. La distribución del estado serológico frente a $T$. gondii de donante y receptor se muestra en la tabla 1.

El empleo de donantes seropositivos en receptores seronegativos mostró una tendencia hacia un mejor pronóstico tras el TC que otras combinaciones. Sin embargo, el análisis univariante no puso de manifiesto una diferencia estadísticamente significativa entre los grupos respecto a la mortalidad total $(\mathrm{p}=0,075$ en la comparación global).

Si se considera la combinación donante (-)/receptor (-) como categoría de referencia, los HR multivariantes de mortalidad total tras el TC fueron 0,71 (IC95\%, 0,39-1,30) para la combinación donante $(+) /$ receptor $(-) ; 1,05($ IC95\%, 0,67-1,63) para la combinación donante $(-) /$ receptor $(+)$ y $1,22(\mathrm{IC} 95 \%, 0,79-1,89)$ para la combinación donante $(+) /$ receptor $(+)$.

\section{DISCUSIÓN}

En esta cohorte unicéntrica de 657 receptores de TC seguidos durante una media de más de 8 años tras la intervención, los pacientes seropositivos frente a $T$. gondii mostraron una moderada reducción de la supervivencia no ajustada en comparación con los pacientes seronegativos. La asociación perdió su significación estadística tras el ajuste multivariante por factores demográficos (edad y sexo); otros modelos de regresión que incluyeron un espectro más amplio de covariantes tampoco pudieron demostrar un efecto independiente del estado serológico frente a $T$. gondii sobre la supervivencia tras el TC. Estos resultados sugieren que la asociación entre ambas variables está fuertemente condicionada por un sesgo de confusión derivado de diferencias significativas en las características clínicas basales de los grupos comparados. En esta serie, los pacientes seropositivos frente a $T$. gondii presentaban mayor media de edad ${ }^{8}$ y mayor prevalencia de condiciones clínicas adversas, como diabetes mellitus ${ }^{9}$ o seropositividad frente a citomegalovirus ${ }^{10}$; además, el empleo de tacrolimus ${ }^{11}$ fue más frecuente entre los pacientes seronegativos.

Arora et al. ${ }^{3}$ plantearon por primera vez la hipótesis de que la seropositividad frente a $T$. gondii podría ser un factor pronóstico adverso en los receptores de TC. Basándose en una serie de 288 pacientes que recibieron un TC en un único centro entre 1994 y 2005, a los cuales se les hizo un seguimiento durante una media de 5,5 años, estos autores describieron un asociación estadísticamente significativa e independiente entre la seropositividad frente a $T$. gondii y mayor riesgo de mortalidad tardía (> 1 año) tras la intervención (HR multivariante $=1,9$ ). Este resultado se atribuyó a la mayor incidencia de enfermedad vascular del injerto (HR multivariante $=2,7$ ) y muerte por esta condición (HR multivariante $=4,4)$. Para explicar sus hallazgos, los autores proponen una hipótesis fisiopatológica, por el momento no confirmada, según la cual la infección crónica por T. gondii contribuiría al desarrollo de la enfermedad vascular del injerto mediante la estimulación de diversas respuestas inmunológicas.

Algunos autores ${ }^{12}$ cuestionaron el análisis de Arora et al. ${ }^{3}$ por dudas en relación con la metodología estadística empleada para el control de potenciales sesgos de confusión. Además, dos análisis unicéntricos posteriores ${ }^{4}, 5$ no pudieron reproducir sus resultados. Contrariamente al estudio inicial, Doesch et al. ${ }^{5}$ describieron en su serie de 344 pacientes que recibieron un TC entre 1989 y 2008, a los cuales se les hizo un seguimiento de una media de 5,7 años, mayor supervivencia en individuos seropositivos frente a $T$. gondii. En otra cohorte unicéntrica de 582 pacientes trasplantados entre 1984 y 2011 con una media de seguimiento de 8,3 años, Van Hellemond et al. ${ }^{4}$ observaron un incremento de mortalidad no ajustada en receptores seropositivos frente a $T$. gondii. Sin embargo, de modo similar a lo observado en este análisis, esa asociación perdía su significación estadística tras el ajuste multivariante. Al igual que en esta serie, los 
pacientes seropositivos de la cohorte de Van Hellemond et al. ${ }^{4}$ presentaban mayor media de edad y mayor prevalencia de comorbilidades adversas que los pacientes seronegativos.

Podría argumentarse que la incapacidad de los modelos multivariantes para detectar un efecto independiente de la seropositividad frente a $T$. gondii sobre la supervivencia tras el TC se debe a un poder estadístico insuficiente. En la opinión de los autores, esta hipótesis es muy improbable, habida cuenta de que el tamaño muestral de esta serie, el número de episodios y la duración del seguimiento son mayores que en el estudio de Arora et $\mathrm{al}^{3}$. Cabe destacar, además, que la fuerza de la asociación estadística es baja -los HR multivariantes varían entre 1,09 y 1,12, según el modelo seleccionado-, lo que no apoya una relación causal. No obstante, las discrepancias entre estos resultados y otros estudios previos ${ }^{3,5}$ han de interpretarse en el contexto de una significativa heterogeneidad de las poblaciones estudiadas, una prevalencia variable de seropositividad frente a T. gondii y variaciones intercentros en cuanto a los regímenes de quimioprofilaxis.

En esta serie no se ha observado un efecto significativo del estado serológico frente a T. gondii sobre la incidencia de enfermedad vascular del injerto ni muerte por causas cardiacas. Este hallazgo es coherente con los dos estudios más recientes ${ }^{4,5}$, pero, como se ha expuesto anteriormente, resulta discrepante con el trabajo inicial ${ }^{3}$. Cabe destacar, sin embargo, que se ha observado un moderado incremento del riesgo de rechazo agudo entre los pacientes seropositivos frente a $T$. gondii. Es conocido que la infección crónica por $T$. gondii es un estímulo proinflamatorio que incrementa la producción de interleucina 12 e interferón gamma por el sistema inmunitario del huésped ${ }^{13}$, por lo que, hipotéticamente, podría ser un desencadenante para el rechazo. En todo caso, este moderado incremento de la incidencia de rechazo agudo no se tradujo en un incremento significativo de la mortalidad; es más, el rechazo agudo fue una causa infrecuente de muerte en esta serie, en la cual fue responsable únicamente del $5 \%$ de todos los fallecimientos registrados. Este hecho paradójico podría ser atribuible a que la mayoría de los episodios de rechazo se detectaron en las biopsias de protocolo antes de causar síntomas o disfunción del injerto y, aun así, se trataron agresivamente.

El análisis univariante detectó un incremento de la incidencia no ajustada de neoplasias tras el TC entre los pacientes seropositivos frente a $T$. gondii. Al igual que en el caso de la mortalidad total, la significación estadística de esta asociación desapareció tras el ajuste multivariante, lo que sugiere por tanto que, de nuevo, esta sería atribuible a un sesgo de confusión derivado de una distribución asimétrica de los factores de riesgo de neoplasias, sobre todo la edad, entre los grupos. Hasta el momento, no existe evidencia de que la infección por $T$. gondii y/o la quimioprofilaxis frente a este germen sean potencialmente carcinógenos.

Este análisis tampoco ha puesto de manifiesto un impacto significativo de la concordancia donante-receptor respecto al estado serológico frente a $T$. gondii sobre la supervivencia tras el TC. Este resultado ha de tomarse con cautela dada la exclusión de casi una tercera parte de los pacientes en que el estado serológico del donante era desconocido, pero, aun teniendo en cuenta esta limitación, resulta concordante con los estudios previos $3,4,5$. La ausencia de un efecto pronóstico negativo del implante de un injerto procedente de un donante seropositivo frente a $T$. gondii en un receptor seronegativo se ha expuesto como argumento contrario a una hipotética influencia del estado serológico frente a $T$. gondii en el pronóstico tras el TC 2 .

\section{Limitaciones y fortalezas}

Este estudio presenta algunas limitaciones. Dada su naturaleza retrospectiva, está expuesto a los sesgos de selección e información inherentes a este tipo de investigación. Además, dado su carácter unicéntrico, sus resultados quizá no sean directamente extrapolables a otras poblaciones. Se ha realizado un exhaustivo análisis multivariante y se han tratado de controlar potenciales sesgos de confusión. Sin embargo, no se puede descartar que otras covariables no testadas pudiesen haber influido en las asociaciones estadísticas observadas. La validez del análisis sobre el 
impacto pronóstico del estado serológico frente a $T$. gondii del receptor es limitada dado que este dato se desconocía en una tercera parte de los individuos estudiados. Además, la falta de información sobre la cumplimentación real de la quimioprofilaxis frente a $T$. gondii ha impedido extraer conclusiones al respecto. Por último, el protocolo de este centro no contempla la realización de determinaciones serológicas seriadas ni pruebas de detección de ADN para la monitorización de la infección por $T$. gondii en pacientes trasplantados; por este motivo, no se ha podido analizar la incidencia de seroconversión o primoinfección por $T$. gondii tras el TC ni establecer una correlación entre esta y los episodios de rechazo agudo o los cambios en el tratamiento inmunosupresor.

En cuanto a las fortalezas del presente trabajo en comparación con otros estudios previos de naturaleza similar, cabe destacar su elevado tamaño muestral y largo periodo de seguimiento, así como el valor añadido de la confirmación de hallazgos obtenidos en otras poblaciones a este medio y el impulso que representa para la fuerza de los argumentos revocatorios expuestos en contra de la hipótesis de un efecto pronóstico independiente de la serología frente a $T$. gondii sobre el pronóstico de los receptores de TC.

\section{CONCLUSIONES}

En este estudio, los receptores de TC seropositivos frente a $T$. gondii presentaron una supervivencia no ajustada menor que los receptores seronegativos. Más que a una asociación causal real, estos resultados parecen atribuibles a un sesgo de confusión derivado de mayor media de edad en el momento del TC y mayor prevalencia de comorbilidades asociadas; de hecho, dos modelos multivariantes diferentes no pudieron demostrar un efecto independiente del estado serológico frente a $T$. gondii del receptor sobre la supervivencia tras el TC. No parece que exista, en definitiva, una evidencia científica firme para recomendar una modificación sustancial de la actitud terapéutica que actualmente se sigue respecto a los receptores de TC que presentan seropositividad frente a $T$. gondii. No obstante, en vista de la discrepancia de resultados entre diferentes series unicéntricas, el análisis de los registros multicéntricos puede resultar interesante para resolver la controversia en torno a esta cuestión.

\section{CONFLICTO DE INTERESES}

Ninguno.

\section{AGRADECIMIENTOS}

Los autores agradecen a Zulaika Grille-Cancela, Paula Blanco-Canosa, Cristina Costa-Graña, Carmen Naya-Leira y Pilar Fariñas-Garrido su colaboración en el estudio.

\section{BIBLIOGRAFÍA}

1. González-Vílchez F, Segovia Cubero J, Almenar L, Crespo-Leiro MG, Arizón JM, Villa A, et al. Registro Español de Trasplante Cardiaco. XXVI Informe Oficial de la Sección de Insuficiencia Cardiaca y Trasplante Cardiaco de la Sociedad Española de Cardiología (1984-2014). Rev Esp Cardiol. 2015;68:1008-21.

2. Kittleson MM, Kobashigawa J. Toxoplasma gondii exposure in the heart transplant recipient: good, bad or indiferent?. Transplantation. 2013;96:1025.

3. Arora S, Jenum PA, Aukrust P, Rollag H, Andreassen AK, Simonsen S, et al. Pre-transplant Toxoplasma gondii seropositivity among heart transplant recipients is associated with an increased risk of all-cause and cardiac mortality. J Am Coll Cardiol. 2007;50:1967-72.

4. Van Hellemond JJ, van Domburg RT, Caliskan K, Birim O, Balk AH. Toxoplasma gondii serostatus is not associated with impaired long-term survival after heart transplantation. Transplantation. 2013;96:1052-8. 
5. Doesch AO, Ammon K, Konstandin M, Celik S, Kristen A, Frankenstein L, et al. Negative pretransplant serostatus for Toxoplasma gondii is associated with impaired survival after heart transplantation. Transpl Int. 2010;23:382-9.

6. Stewart S, Winters GL, Fishbein MC, Tazelaar HD, Kobashigawa J, Abrams J, et al. Revision of the 1990 working formulation for the standardization of nomenclature in the diagnosis of heart rejection. J Heart Lung Transplant. 2005;24:1710-20.

7. Kobashigawa J, Crespo-Leiro MG, Ensminger SM, Reichenspurner H, Angelini A, Berry G, et al. Consensus Conference Participants. Report from a consensus conference on antibody-mediated rejection in heart transplantation. J Heart Lung Transplant. 2011;30:252-69.

8. Lund LH, Edwards LB, Kucheryavaya AY, Dipchand AI, Benden C, Christie JD, et al. International Society for Heart and Lung Transplantation. The Registry of the International Society for Heart and Lung Transplantation: Thirtieth Official Adult Heart Transplant Report--2013;focus theme: age. J Heart Lung Transplant. 2013;32:951-64.

9. Russo MJ, Chen JM, Hong KN, Stewart AS, Ascheim DD, Argenziano M, et al, Columbia University Heart Transplant Outcomes Research Group. Survival after heart transplantation is not diminished among recipients with uncomplicated diabetes mellitus: an analysis of the United Network of Organ Sharing database. Circulation. 2006;114:2280-7.

10. Hussain T, Burch M, Fenton MJ, Whitmore PM, Rees P, Elliott M, et al. Positive pretransplantation cytomegalovirus serology is a risk factor for cardiac allograft vasculopathy in children. Circulation. 2007;115:1798-805.

11. Guethoff S, Meiser BM, Groetzner J, Eifert S, Grinninger C, Ueberfuhr P, et al. Ten-year results of a randomized trial comparing tacrolimus versus cyclosporine a in combination with mycophenolate mofetil after heart transplantation. Transplantation. 2013;95:629-34.

12. Flores-Ríos X, Paniagua-Martín MJ, Muñiz-García J, Crespo-Leiro MG. Pre-transplant Toxoplasma gondii seropositivity among heart transplant recipients and mortality. J Am Coll Cardiol. 2008;51:1827.

13. Dupont CD, Christian DA, Hunter CA. Immune response and immunopathology during toxoplasmosis. Semin Immunopathol. 2012;34:793. 